\title{
Renewable energy sources for gas preheating
}

\author{
Sebastian Englart ${ }^{1, *}$, Andrzej Jedlikowski ${ }^{1}$, Wojciech Cepiński ${ }^{1}$, and Marek Badura ${ }^{1}$ \\ ${ }^{1}$ Wrocław University of Science and Technology, Faculty of Environmental Engineering, \\ Department of Air Conditioning, Heating, Gas Engineering and Air Protection, \\ ul. Norwida 4/6, 50-373 Wrocław, Poland
}

\begin{abstract}
To ensure proper gas supply parameters, to the polish natural gas distribution network, which includes about 900 pressure reduction stations (PRS), requires high energy consumption for gas heating, that amounts to approx. $700 \mathrm{TJ} /$ year. This value can be significantly reduced by using renewable energy sources (e.g. ground heat exchangers, heat pumps) in polish gas preheating PRS. This paper presents the analysis of some applications for gas preheating by using gas absorption heat pump and combination of heat pump and ground heat exchanger. The results confirm a noticeable heat energy savings at the PRS by $44 \%$.
\end{abstract}

\section{Introduction}

Currently in Poland there are located about 900 gas stations [1]. In accordance with the applicable regulations, the main division of the gas station is carried out according to the maximum operating pressure (MOP) [2]. In Poland, the gas transmission takes place under a pressure established contractually as high and amounting to $6.3 \mathrm{MPa}$ or $8.4 \mathrm{MPa}$, respectively. On the other hand, a distribution network ensuring gas supply to customers usually operates at medium or low pressure. Depending on the two inlet pressure groups, a distinction can be made between 1st degree (high inlet pressure) and 2nd degree (medium inlet pressure) reduction stations [2,3]. Gas reduction is a key process that takes place at pressure reduction station (PRS) and it is based on the isenthalpic throttling of natural gas across a valve. During that operation, the adiabatic expansion without work occurs, with a simultaneous decrease of temperature, caused by Joule-Thomson effect [4]. However, this phenomenon may have some negative consequences. Some amounts of water vapor, that could be present in pipelines, may start to condense and in extreme cases may start to solidify (freezing and hydrate formation). As a result, gas hydrates may enter inside the fittings and equipment of PRS. Such situation is dangerous, as hydrates can cause a significant clogging of pipelines or blockage of reduction valves [4]. The elimination of negative effects during the reduction of gas pressure is associated with the installation of appropriate heating devices. The most popular system for gas preheating is composed of a gas boiler and a shell-and-tube-type heat exchanger. The energy demand for gas preheating in such a system constitutes a significant part of the operating costs of the PRS. Osiadacz et al. [4] reported that the amount of gas needed to produce energy for gas preheating can be as much as approx. $1.5 \%$ of the amount of gas transmitted through PRS.

*Corresponding author: sebastian.englart@pwr.edu.pl 
Kostowski [5] discussed the use of turboexpanders by making detailed thermodynamic and economic analyses of the possibilities of obtaining electric energy in that way. Kostowski and Usón [6] proposed also combining the work of a two-stage expander with a co-generation system. The electricity production was also discussed by Rataj and Gebhardt [7]. Authors presented the possibility of use of the turbines and engines systems as equipment for pressure reduction at gas stations. Nowadays, many different systems for electricity production are available on the market. However, other interesting solutions may also be found. For example, Gascontrol Polska [8] informs about the possibility of using thermoelectric generators to ensure the supply of electricity in an amount that secures the demand for metering and data transmission systems at PRS. The other way of improving energy efficiency of PRS is related to the use of renewable energy sources for gas preheating. Osiadacz et al. [9] discussed the use of several different systems equipped with such devices as: solar collectors, heat pumps, shell-and-tube heat exchanger, heat accumulator and turboexpander. Even more complex systems were considered in international literature. Farzaneh-Gord et al. [10] presented the feasibility of employing solar heat storage system equipped with controllable heaters. Cascio et al. [11] discussed the use of a novel configuration of PRS equipped with sun-tracking parabolic trough solar collectors, coupled with thermal energy storage. Different configuration was proposed by Farzaneh-Gord et al. in [12] - they discussed the utilization of vertical ground-coupled heat pump system to preheat natural gas stream.

Generally, there are many solutions aimed at achieving significant savings for PRS operation. This issue is of particular importance for the Polish gas system, where the volume of distributed gas amounted to about 11.5 billion $\mathrm{m}^{3}$ in 2017 . In that system, circa 900 gas stations are used [1], but the application of modern energy-saving technologies is negligible. For that reason, the authors decided to propose two alternative systems for gas preheating and reducing energy consumption at PRS. The first solution is based on gas absorption heat pump (GAHP) and the other is a combination of heat pump and ground heat exchanger (GHE). These proposals were used to analyse the operation of the gas station and to calculate the energy savings.

\section{Proposals for the use of renewable energy sources at PRS}

The authors of this paper decided to analyze the possibility of using appliances burning gaseous fuels, in which primary energy (contained in gas) is processed on site. This avoids transmission losses and achieves higher efficiency compared to other energy sources, including electricity generated in coal-fired power plants in Poland.

\subsection{Heat pump}

GAHP is a device characterized by a low primary energy coefficient and low emissions (based on modern absorption system technology). The system uses energy from gas combustion and renewable energy (from air, ground or water). The gas heat pump releases the sum of these forms of energies into the heating system and thus achieves high efficiency. 


\subsection{Air direct-contact, gravel, ground heat exchanger}

For over 30 years, Wrocław University of Science and Technology has been conducting research on effective use of natural heat energy from a shallow ground. It was found, that in the central European climate, the ground temperature at a depth of approx. $4-5 \mathrm{~m}$ is practically stable throughout the year and close to the average temperature of outside air (about $+10 \pm 1.5^{\circ} \mathrm{C}$ ). For that reason, the use of a ground heat exchanger can be a very effective solution for heating processes [13].

In typical configuration of that heat exchanger, the outside air flows horizontally through an accumulation bed with a length of 3-5 $\mathrm{m}$. As a result of contact between the flowing air and the heat exchanger bed material, the temperature of air changes. This results in heating of outside air even from $-20^{\circ} \mathrm{C}$ to $0^{\circ} \mathrm{C}$ in winter or cooling of air from $+30^{\circ} \mathrm{C}$ to $+20^{\circ} \mathrm{C}$ in summer. The pressure drop on that type of ground heat exchanger is small and ranges from $100 \mathrm{~Pa}$ to about $250 \mathrm{~Pa}$ [13].

\subsection{Solution idea}

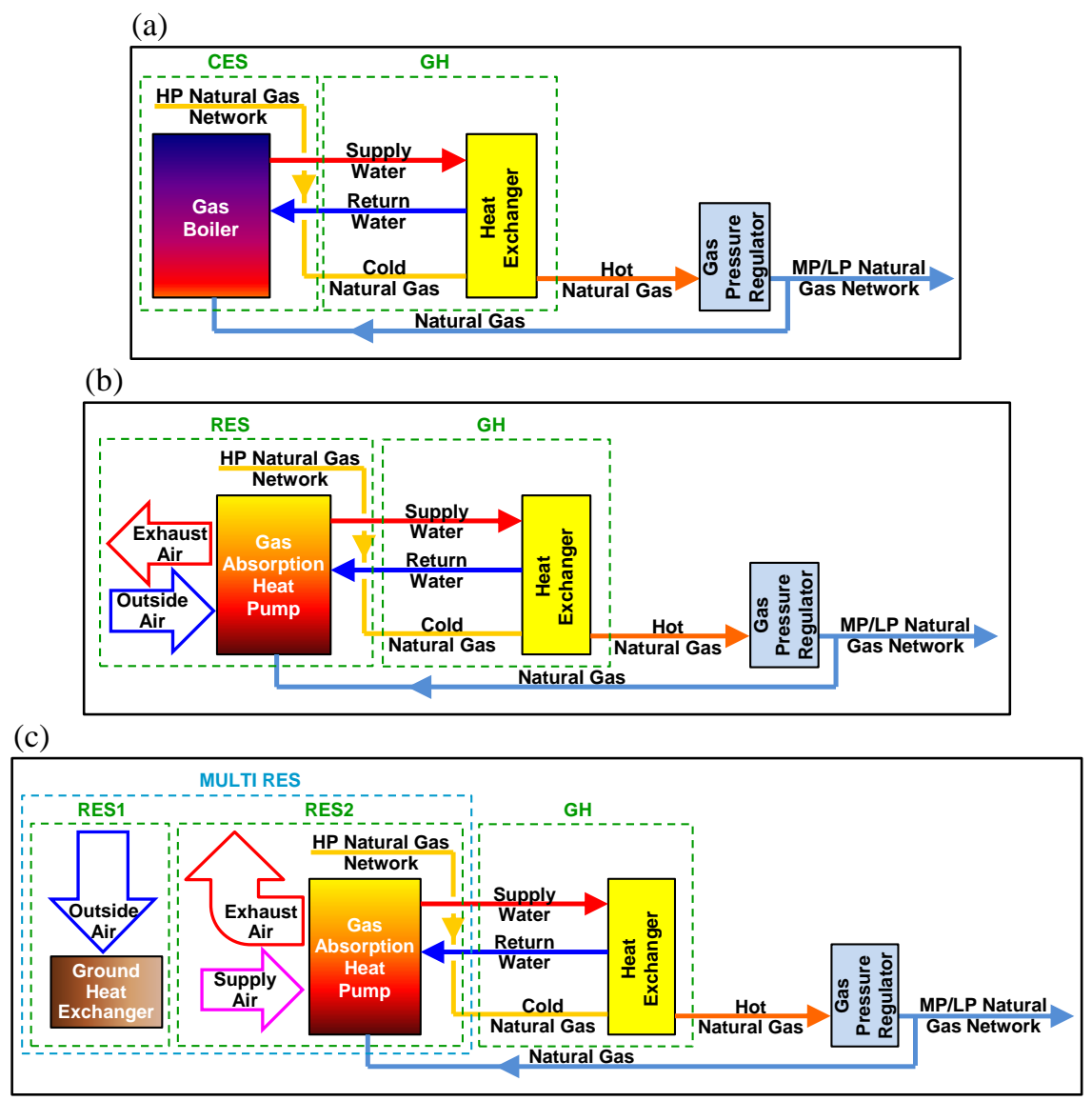

Fig. 1. Schematic diagrams of considered gas preheating systems equipped with: (a) conventional energy source (Gas Boiler), (b) renewable energy source (Gas Absorption Heat Pump), (c) renewable energy source (Gas Absorption Heat Pump and Ground Heat Exchanger). (Abbreviations:

$\mathrm{CES}$ - conventional energy source, GH - gas heating, HP - high pressure, LP - low pressure, MP - medium pressure, RES - renewable energy source). 
Fig. 1. presents the diagrams of considered PRS preheating systems with conventional and renewable energy sources. A typical device used to preheat gas is traditional gas boiler (Fig. 1 (a)), operating at relatively high temperature parameters. The increase of efficiency of such device is possible by lowering the operating parameters and recovering latent heat from flue gases through a condensation process (i.e. by the use of condensing boiler). In such case, the use of a larger gas heater with a larger heat transfer area is necessary.

Recently, in order to reduce energy consumption, other appliances supported by renewable energy have started to be of interest $[4,9-12,14,15]$. The first proposal for the use of renewable energy sources is based on air-to-water or brine-to-water gas-fired absorption heat pump (GAHP, Fig. 1 (b)).

The second solution is based on addition of another renewable energy source - a system of air-to-water gas absorption heat pump coupled with ground heat exchanger (GHE, Fig. 1 (c)). As a result of such cooperation between renewable energy devices, fluctuations in the air temperature flowing into the evaporator and used for combustion are much smaller (both in the daily and seasonal cycle). That kind of system clearly improves the operating conditions of GAHP and efficiency of the device, while increasing its service life and reliability.

The above mentioned configurations were used to carry out an analysis of the possibility of reducing the energy demand for gas preheating at PRS.

\section{Analysis of the possibility of reducing the energy demand}

\subsection{Assumptions for analysis}

The analysis was carried out for a high-pressure gas reduction station using calculation formulas (1)-(5) supplemented by assumed and calculated design data.

The gas density under normal conditions was determined as follows:

$$
\rho_{n}=d \cdot \rho_{p}
$$

where:

$d \quad$ - relative gas density, $d=0.58$,

$\rho_{p} \quad-$ air density at $T_{i n}=273.15 \mathrm{~K}, \rho_{p}=1.293 \mathrm{~kg} / \mathrm{m}^{3}$,

The required gas temperature increase was determined from the assumptions for the gas station data:

$$
\Delta T_{2}=T_{\text {out }}-T_{\text {in }}^{\min }
$$

where:

$T_{i n}^{\min }-$ minimum input gas temperature, $T_{i n}^{\min }=273.15 \mathrm{~K}$,

$T_{\text {out }}$ - output gas temperature, $T_{\text {in }}^{\mathrm{min}}=278.15 \mathrm{~K}$,

The impact of the Joule-Thomson effect was calculated from the formula:

$$
\Delta T_{1}=\left(P_{\text {in }}-P_{\text {out }}\right) \cdot \Delta T_{2}
$$

where:

$P_{\text {in }}$ - input gas pressure, $P_{\text {in }}=6.3 \mathrm{MPa}$, 
$P_{\text {out }}$ - output gas pressure $P_{\text {out }}=0.4 \mathrm{MPa}$,

$\Delta T_{2}-$ required gas temperature increase, $\Delta T_{2}=5 \mathrm{~K}$,

The required gas station temperature increase taking into account the Joule-Thomson effect was calculated as follows:

$$
\Delta T_{g}=\Delta T_{1}+\Delta T_{2}
$$

where:

$\Delta T_{1}-$ Joule-Thompson effect, $\Delta T_{1}=29.5 \mathrm{~K}$,

$\Delta T_{2}$ - required gas temperature increase, $\Delta T_{2}=5 \mathrm{~K}$,

The heating capacity for a gas station is determined as follows:

$$
W=\frac{Q \cdot \Delta T_{g} \cdot \rho_{n} \cdot c_{p}}{\eta \cdot 3600}
$$

where:

$Q \quad$ - design capacity of gas pressure reduction station, $Q=5300 \mathrm{~m}^{3} / \mathrm{h}$,

$\Delta T_{g}$ - the required gas temperature increase including Joule-Thomson effect, $\Delta T_{g}=35 \mathrm{~K}$,

$\rho_{n} \quad$ - gas density, $\rho_{n}=0.75 \mathrm{~kg} / \mathrm{m}^{3}$,

$c_{p} \quad-$ specific heat of gas at $T_{i n}=273.15 \mathrm{~K}$ and $P=0.1013 \mathrm{MPa}, c_{p}=2160 \mathrm{~J} /(\mathrm{kgK})$,

$\eta \quad$ - effectiveness of the gas preheater, $\eta=0.85$,

As a result of the calculations carried out, it was established that the demand for heating energy of the station for gas heating amounted to $97 \mathrm{~kW}$.

In the analysis of the year-round operation, the mean times of occurrence of the given outside air temperatures at the average relative humidity were used. Then, for different parameters of medium operation in the installation, the operation of three gas heating systems (gas boiler, gas absorption heat pump using energy from the outside air or from the ground through the ground heat exchanger) was compared (Fig. 1).

The calculations assume two modes of year-round operation of the gas station:

- Constant performance throughout the period for industrial needs,

- Variable performance as a function of the demand resulting from the living needs (preparation of meals, space heating and domestic hot water preparation).

\subsection{Heating capacity of gas absorption heat pump}

Power demand of the GAHP depends on the temperature of the heat source and the heat demand for gas preheating (reliant on gas flow). The calculation must also take into account the incoherence of the pump, which is caused by variation of the outside air temperature. In other words, as the outside air temperature drops, the heating capacity of the GAHP decreases and a simultaneous increase of energy demand, due to the growing consumption of gas, is observed. In addition, the relative humidity of the outside air also changes with the increase in temperature, which has a significant effect on the evaporator power. For example, a heating device operating at parameters $40 / 30^{\circ} \mathrm{C}$ at an outside air temperature of $-18^{\circ} \mathrm{C}$ will have a heating capacity about $20 \%$ lower than outside air temperature of $0^{\circ} \mathrm{C}$. Moreover, by changing the operating parameters from $40 / 30^{\circ} \mathrm{C}$ to $65 / 55^{\circ} \mathrm{C}$, the heating capacity of the device will decrease by approx. $30 \%$ for equal outside air temperatures. For 
this reason, it is recommended not only to select systems with low operating temperature parameters, but also to combine them with devices such as GHE. This allows the GAHP evaporator to operate at temperatures not lower than $0^{\circ} \mathrm{C}$ with greater power and effectiveness throughout the year. Such solution allows to select heat pump with a lower heating capacity and ensures that energy demand is fully covered throughout the year with the same unit.

\subsection{Effectiveness of gas absorption heat pump}

The overall effectiveness of GAHP is expressed as the ratio of the heating capacity of whole device to the heat taken from the gas burner (calorific value of the gas), taking into account its effectiveness.

The gas utilization effectiveness of GAHP is determined as follows:

$$
G U E=\frac{Q_{G A H P}}{G_{G A H P}}
$$

where:

$Q_{\text {GAHP }} \quad$ - the power supplied by the heat pump, $\mathrm{kW}$

$G_{G A H P}$ - energy calculated on the basis of the calorific value, $\mathrm{kW}$

The above mentioned process takes place with a relatively small share of electric power needed for the operation of fans and control system.

\subsection{Results of calculation}

Fig. 2 presents the relationship between effectiveness and outside air temperature for the three considered variants of gas preheating systems, under different conditions of their operation. As can be seen, even a simple replacement of the conventional gas-fired boiler with a condensing appliance increases the effectiveness of the entire system (from 0.90 to $1.10)$.

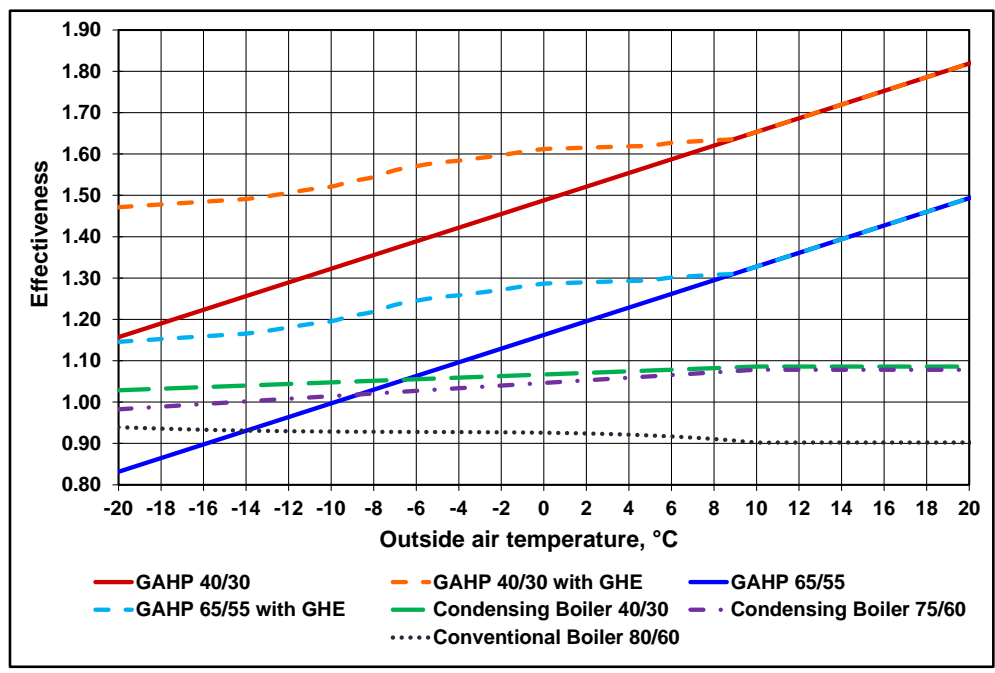

Fig. 2. Effectiveness of the considered gas preheating systems expressed as a function of the outside air temperature. 


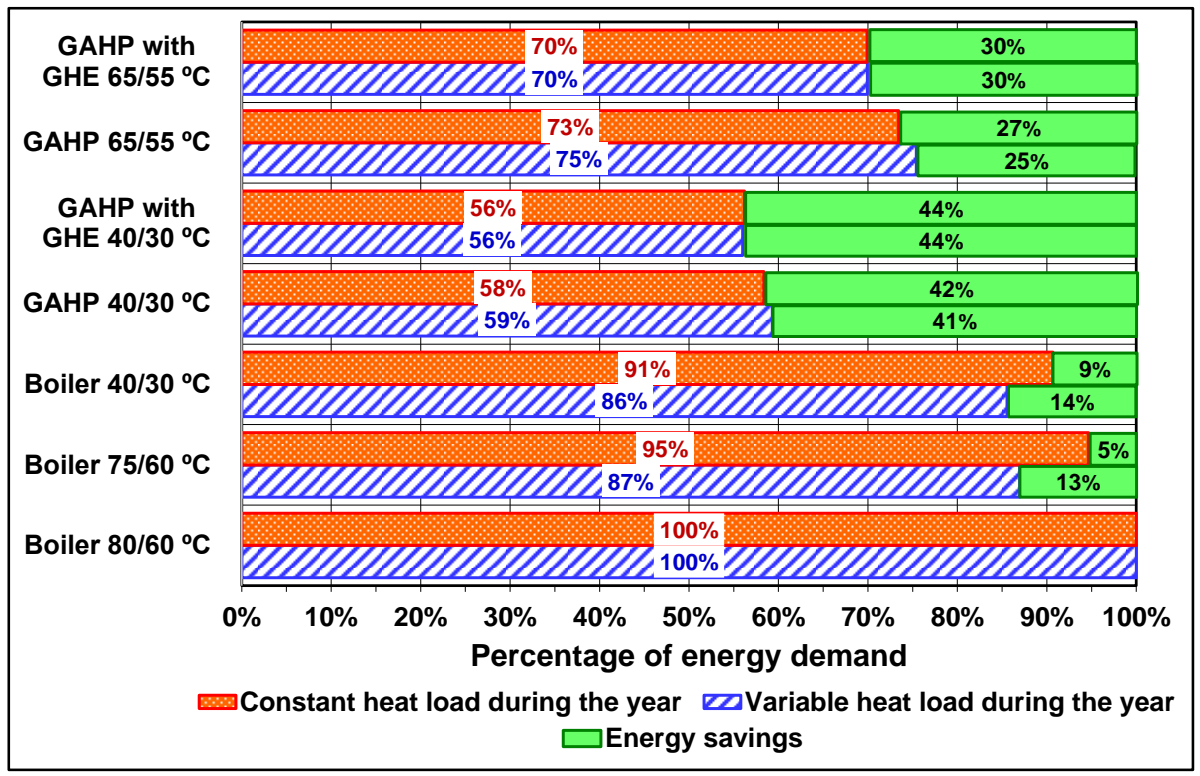

Fig. 3. Comparison of energy savings of considered gas preheating systems with respect to the conventional energy source (gas boiler operating under temperature parameters $80 / 60^{\circ} \mathrm{C}$ ).

In case of GAHP, the application of such solution allows to achieve a noticeable increase in heating effectiveness (up to 1.8). In the range of low outside air temperatures, the effectiveness of the system may be further improved (by about 50\%) when the cooperation of GAHP and GHE is taken into account.

Fig. 3 presents the results of a comparative analysis of the considered gas preheating systems with respect to the conventional gas boiler. Generally, the use of any of the proposed systems (condensing boiler, GAHP or GAHP with GHE) may result in the energy savings in gas consumption (from 5\% to more than $40 \%$ per year, depending on the PRS load operation).

In terms of purchase cost, the most effective solution is the use of a condensing boiler operating under low temperature conditions, where gas consumption can be reduced up to $14 \%$. However, the most economical in terms of gas demand is the system of GAHP cooperating with GHE. For that variant, a $44 \%$ reduction of gas consumption is possible.

\section{Conclusions}

The solutions presented in this paper, based on renewable energy sources, may allow for significant reduction in primary energy consumption in an environmentally friendly way in about 900 PRS located in Poland. The safe operation of gas distribution systems requires a high energy demand for gas preheating of approx. 700 TJ/year. An economic analysis carried out by using low-temperature gas boilers, heat pumps and ground heat exchangers, in order to reduce the energy demand.

The performed analysis allow to present the following conclusions:

- Replacement of a traditional gas-fired boiler (CES) with a low-temperature boiler (equipped with a heat exchanger with a correspondingly higher heating capacity) allows for a reduction in energy demand from $5 \%$ to $14 \%$,

- The application of a gas heat pumps, as an RES option to the traditional gas boiler, enables to gas consumption up to $27-42 \%$, 
- The extension of the gas preheating system with an additional ground heat exchanger, used as a heat source for the heat pump (Multi RES option in Figure 1(c), allows for greater energy savings in gas consumption between $30-44 \%$,

The analysis confirms the necessity of further researches on additional RES solutions for more energy savings in the required energy for preheating the natural gas.

This work was supported by The Faculty of Environmental Engineering, Wroclaw University of Science and Technology, Poland (No. 0401/0055/18).

\section{References}

1. Gaz System, Przesyt w liczbach. Dane za rok kalendarzowy 2017 - stan na dzień 31 grudnia 2017 / Transmission in numbers. Data for the calendar year 2017 - as at 31 December 2017, http://www.gaz-system.pl/strefa-klienta/systemprzesylowy/przesyl-w-liczbach/, (accessed: 29.12.2018)

2. K. Bąkowski, Sieci i instalacje gazowe, poradnik projektowania budowy i eksploatacji (WNT, Warszawa, 2007)

3. Górnośląski Zakład Obsługi Gazownictwa sp. Z o.o., Stacje gazowe, https://www.gzog.pl/stacje-redukcyjno-pomiarowe, (accessed: 04.01.2019)

4. A. J. Osiadacz, M. Chaczykowski, M. Kwestarz, N. Isoli, Gas, Water \& Sanitary Engineering 4, 122-126 (2018)

5. W. Kostowski, Journal for Theory and Application in Mechanical Engineering 52, 429-440 (2010)

6. W. J. Kostowski, S. Usón, Appl. Energy 101, 58-66 (2013)

7. M. Rataj, Z. Gebhardt, Nafta-Gaz 4, 332-337 (2009)

8. Gascontrol Polska, K. Górny, Turboekspandery i termogeneratory, http://gascontrolpolska.pl/energetyka/turboekspanery-i-termogeneratory/ (accessed: 04.01.2019),

9. A. J. Osiadacz, M. Kwestarz, M. Chaczykowski, Gas, Water \& Sanitary Engineering 6, 202-206 (2018)

10. M. Farzaneh-Gord, A. Arabkoohsar, M. Deymi Dasht-bayaz, L. Machado, R.N.N. Koury, Renew. Energy 72, 258-270 (2014)

11. E. L. Cascio, Z. Ma, C. Schenone, Renew. Energy 128, 177-187 (2018)

12. M. Farzaneh-Gord, R. Ghezelbash, M. Sadi, A. Jabari, Energy 112, 998-1014 (2016)

13. W. Cepiński, M. Besler, E3S Web Conf. 22, 00027 (2017)

14. K. Bryś, T. Bryś, M. A. Sayegh, H. Ojrzyńska, Energ. Buildings 165, 64-75 (2018)

15. M. A. Sayegh, P. Jadwiszczak, B. P. Axcell, E. Niemierka, K. Bryś, H. Jouhara, Energ. Buildings 166, 122-144 (2018) 